\title{
Completion of fit notes by GPs: a mixed methods study
}

\begin{tabular}{|r|l|}
\hline Journal: & Perspectives in Public Health \\
\hline Manuscript ID: & RSH-15-0041.R1 \\
\hline Manuscript Type: & Original Research Paper \\
\hline Keywords: & General Practitioner, fit note, sickness certification, employees \\
\hline Abstract: & $\begin{array}{l}\text { Aims } \\
\text { The aim of this study was to investigate the completion of fit notes by UK } \\
\text { GPs. A series of actual fit notes issued to employed patients were } \\
\text { examined, and their GPs' reflections and experiences of fit note completion } \\
\text { explored. } \\
\text { Methods } \\
\text { A mixed methods design was used. Data were collected from copies of } 94 \\
\text { fit notes issued to employed patients by eleven GPs, and from } 86 \\
\text { questionnaires completed by these GPs reflecting on the fit notes they had } \\
\text { issued. Face-to-face interviews were then conducted with each GP. } \\
\text { Results } \\
\text { Fit note completion is not meeting expectations for a number of reasons. } \\
\text { These include: limited knowledge and awareness of the guidance in fit note } \\
\text { completion; problems with the fit note format; lack of mandatory training } \\
\text { in completing fit notes; lack of incentive to change practice; incomplete } \\
\text { implementation of the electronic fit note; GPs' lack of confidence in, and } \\
\text { doubts about the appropriateness of performing this role. } \\
\text { Conclusions } \\
\text { If UK GPs are to continue their contractual responsibility for completing fit } \\
\text { notes, further consideration of their education and training needs is } \\
\text { urgently required. Weaknesses in the design and format of the fit note and } \\
\text { the availability of the electronic version also need to be addressed. }\end{array}$ \\
\hline
\end{tabular}


1

2

3

4

5

6

7

8

9

10

\section{Abstract}

\section{Aims}

The aim of this study was to investigate the completion of fit notes by UK GPs. A series of actual fit notes issued to employed patients were examined, and their GPs' reflections and experiences of fit note completion explored.

\section{Methods}

A mixed methods design was used. Data were collected from copies of 94 fit notes issued to employed patients by eleven GPs, and from 86 questionnaires completed by these GPs reflecting on the fit notes they had issued. Face-to-face interviews were then conducted with each GP.

\section{Results}

Fit note completion is not meeting expectations for a number of reasons. These include: limited knowledge and awareness of the guidance in fit note completion; problems with the fit note format; lack of mandatory training in completing fit notes; lack of incentive to change practice; incomplete implementation of the electronic fit note; GPs' lack of confidence in, and doubts about the appropriateness of performing this role.

\section{Conclusions}

If UK GPs are to continue their contractual responsibility for completing fit notes, further consideration of their education and training needs is urgently required. Weaknesses in the design and format of the fit note and the availability of the electronic version also need to be addressed. 


\section{Introduction}

Sickness certification is a common activity in general practice in the UK, as, apart from the first seven days of absence the GP is responsible for certification, until 28 weeks of absence has been reached. ${ }^{1}$ Certification practice is under increasing scrutiny due to the personal, social and economic costs of sickness absence and work disability and a growing working-age population. ${ }^{2,3}$ In 2010, with these issues in mind, the UK government introduced the 'fit note'. ${ }^{4}$ The purpose of the fit note is to reduce avoidable sickness absence and facilitate return-to-work of those with health problems. ${ }^{4}$ Whereas previously GPs were required to state that a patient was either able to work or not, GPs now have the option of advising that a patient is 'not fit' or that they 'may be fit' for work if appropriate work adjustments can be made. If the 'may be fit' option is selected, GPs are then required to advise on one or more of the following modifications: a phased return to work, altered hours, amended duties, workplace adaptions. GPs should then enter a free-text comment, including the functional effects of the condition, and are advised it may also be useful to enter free-text comments when the patient is 'not fit' for work. There is no longer a 'fit' for work option; instead the GP is mandated to state whether or not they need to assess the patient again on expiry of the fit note. An electronic version of the fit note was to be rolled out by early $2013 .{ }^{5}$

Although the fit note has been generally welcomed by employers and clinicians, studies have indicated that they are not being completed as intendedcompletion of fit notes is not meeting expectations. A quantitative study of fit note comments ${ }^{6}$ revealed a wide variation in use and that few described the functional effects of the condition. A survey of completed fit notes conducted by the Department for Work and Pensions (DWP) ${ }^{7}$ demonstrated that fewer than $7 \%$ had the 'may be fit' option selected, and that modification options, free-text comments and reassessment information were often missing. A survey of employers ${ }^{8}$ has reported that few 


\begin{abstract}
electronic versions are received and that free-text advice is often absent or vague; however, this information was based on general recall rather than specific cases. No studies have examined why GPs are not completing fit notes as intended.

The aim of this study therefore was to examine a series of actual fit notes completed by GPs for employed patients, and their reflections and experiences of fit note completion.
\end{abstract}

\title{
Method
}

Ethical approvals were obtained from Northampton Research Ethics Committee. The study formed part of a larger investigation of the fit note, described elsewhere. ${ }^{9}$

A mixed methods design was used. Data were collected via fit note copies and individual interviews. The aim was to recruit ten GPs representing a range of socio-economic settings. A variety of sampling methods were employed. Written consent was obtained.

GPs were asked to record the first ten 'new' fit notes issued to employed patients (i.e. not continuations of previously issued fit notes), including a minimum of five 'may be fit' notes. Participants sent a copy of each fit note to the research team, having deleted all patient/practice/GP details. Six weeks after issuing the fit note, participants were send-sent a postal questionnaire to rate, and comment on, their completion of each fit note. At the end of the data collection period, each GP took part in a face-to-face interview to explore their experiences and perceptions of the fit note. Interviews were digitally recorded. The topics for the interview quide were initially selected by the research team and study steering group which included two GPs, a patient representative and employer representative. The guide allowed for new topics to be added as the interviews progressed. 
Quantitative data were analysed descriptively. Questionnaire comments were analysed using thematic content analysis. ${ }^{10}$ Interview data were analysed thematically. ${ }^{11}$ Interviews were transcribed verbatim, checked and corrected by the interviewer then uploaded onto Nvivo 10 . The interviewers independently coded a sample of interviews line-by-line, then compared and revised these initial codes. Each interview was then coded and themes identified through constant comparison of the scripts. Themes were discussed, revised where needed and finally agreed.

\section{Results}

\section{Participants}

A total of 272 GP practices were invited to participate in the study, each employing at least one GP. Twelve GPs expressed an interest in the study; one withdrew prior to data collection. The remaining, therefore eleven GPs participated. Four worked in locations representing areas of highest deprivation, five in those representing areas of least deprivation. Six were male, five female. The mean number of years' experience as a GP was 15 (range1.5-26 years).

\section{Fit note data}

Ninety-eight copies of fit notes were submitted. The most frequently specified conditions were

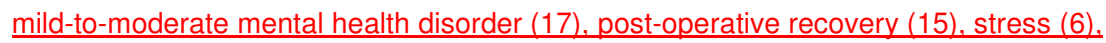
circulatory problem (6), back problem (6), other musculoskeletal problem (6). Of the fit notes submitted, four related to unemployed patients and were excluded from the study, leaving a total of 94 fit notes. Fit note data were sent to the research team in different formats depending on how they had been completed by the GP. Five GPs sent photocopies of handwritten fit 
notes, four sent copies of electronic fit notes, and two sent the fit note details in an Excel format as they were unable to print a copy from their computers.

The results are shown in Table 1. The majority $(n=62,66.0 \%)$ were 'not fit' and $25(26.6 \%)$ were 'may be fit'. Six notes (6.4\%) had neither option selected and one (1.1\%) had both options selected.

The section indicating whether or not the GP needed to assess the patient again at theon expiry of the fit note duration-was completed in $40(42.5 \%)$ cases. In $37(39.4 \%)$ cases the review section was left uncompleted, and in 17 (18.1\%) cases the review section was missing altogether due to the GP using a non-standardised fit note template.

The most common single work modification selected by GPs was 'amended duties', which was selected in 8 cases (50\% of single work modifications). The second most common single work modification selected was 'phased return', found in 5 cases (20\% of single work modifications). 'Altered hours' was selected in two cases, and 'work adaptations' was selected-in one case.

The comment section was completed in 27 (28.7\%) of the fit notes, of which $21(77.8 \%)$ were 'may be fit' notes and four (14.8\%) were 'not fit' notes. One (3.7\%) of the fit notes with a comment had neither of the options selected and one (3.7\%) had both options selected.

\section{Fit Note Comments}

Five distinct categories were identified from analysis of the fit note comments. Some comments covered more than one category. The frequency of categories identified and an example of each are shown in Table 2. The most frequently identified category was 'work-related advice' 

information on health condition' (8 fit notes).

\section{Questionnaire data}

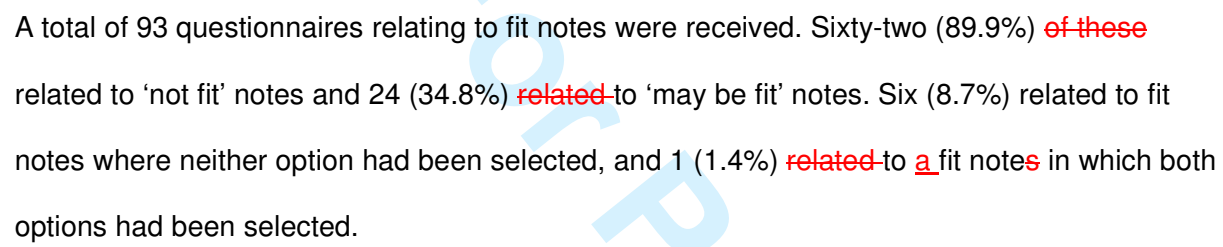

\section{Completion of 'not fit' notes}

Questionnaire responses $(n=62)$ made in regarding to completion of the 'not fit' notes are illustrated in Figure 1.

In $56(90.3 \%)$ cases the GP either agreed or strongly agreed that they had completed the fit note satisfactorily.

In the majority of cases $(n=45,72.6 \%)$ the GP disagreed or strongly disagreed that the patient could have returned to work with modifications. In eight $(12.9 \%)$ cases the GP agreed that this could have been the case, and in 7 cases $(11.3 \%)$ the GP neither agreed nor disagreed.

In $24(38.7 \%)$ cases the GPs were neutral as to whether the fit note was useful in planning the patient's return to work. An equal number 'agreed or strongly agreed' as 'disagreed or strongly disagreed' ( $n=19,30.6 \%$ in each case). 


\begin{abstract}
In almost three quarters of cases $(n=46,74.2 \%)$ the GP disagreed or strongly disagreed that factors other than the patient's presenting health condition influenced their completion of the fit note. Eleven (17.7\%) agreed or strongly agreed.
\end{abstract}

The greater proportion ( $n=38,61.2 \%$ ) agreed or strongly agreed that the fit note explained to the employer how the patient's health condition affected their ability to work. Eleven (17.7\%) disagreed.

\title{
Completion of 'may be fit' notes
}

Questionnaire responses $(n=24)$ made in regarding to the usefulness of the 'may be fit' notes are illustrated in Figure 2.

In all cases the GP either agreed or strongly agreed that they had completed the fit note satisfactorily.

The majority of GPs $(20 ; 83.3 \%)$ agreed or strongly agreed that the fit note was useful in planning the patient's return to work. Two $(8.3 \%)$ were neutral, and two $(8.3 \%)$ disagreed with this statement.

In more than half of cases $(n=15,62.5 \%)$ the GP disagreed or strongly disagreed that factors other than the patient's presenting health condition influenced theirmy completion of theis fit note , seven (29.2\%) were neutral, and two (8.3\%) agreed with this statement. 


\section{Questionnaire comments}

A total of 96 comments were made. Categories including five or more comments, and examples of the content of these categories, are shown in Table 3. Each comment could cover more than one category.

The greater proportion of comments referred to how the GP could have provided further information on their fit note.

Fourteen comments referred to the GPs opinion that there was no further information that could have helped the patient return to work, or that this information was 'not applicable' (these were all related to 'not fit' notes).

Twelve comments referred to GPs' reasons associated withfor issuing a 'not fit' note, and a further twelve to GPs' uncertainty as to whether they had completed the fit note satisfactorily.

Six comments referred to GPs views about their role in fit note completion. 
Five comments referred to reasons for not providing more detail on fit notes and a further five to whenfe GPs had not anticipated the return to work outcome of their patient.

\section{Interview findings}

Interviews took place at the GPs' surgeries between November 2013 and May 2014. Seven interviews were conducted by one researcher, and four by a second researcher. The duration ranged from 25 to 46 minutes (mean 34 minutes). Three main themes related to fit note completion were identified.

\section{Overall perceptions of the fit note consultation}

Not all GPs considered issuing fit notes to be their role and several would have preferred not to have responsibility for them. Many felt considered themselves ill-equipped to make effective use of the fit note and that they had 'more important things' to deal with. Some felt that they had to accept what the patient said at face value, emphasising their role as patient advocate. IHowever they were also reluctant to anger or upset patients if they held a conflicting view, particularly with long-term sickness absence.

I think that it's probably something that is probably in the wrong place with GPs. I think it fundamentally misunderstands what GPs do. I don't think we have either the time or the skills - so the capacity to do the sorts of in depth discussions that we need to do about someone's occupation in the context. (GP_4)

In some cases fit notes were perceived-thought to be unnecessary for example in 'cut and dried' cases such as elective surgery where there was perceived to be an expected set period of absence. 
Participants described how GPs varied in their understanding, completion and management of the fit note, even within the same practice:

I think I'm a little less easy going than other members of the practice maybe - I don't have any audit for this but I could imagine one or two of the others being a little bit more happy than even I am to give sick notes, fit notes. (GP_3)

This variation could also be due to individual preference, time and the location of the practice. GPs in areas where the majority of patients were unemployed might issue more 'not fit' notes, and have a lower 'threshold'.

There were difficulties in providing a consistent approach to fit note completion as 'many people come back for repeat notes to different doctors'. Tracking the fit note on the medical records system relied on accurate coding by each GP. If the initial fit note had been issued in hospital it may not have been recorded on the same system.

Some GPs referred to the fact that many patients had already been absent from work through self-certification by the time they consulted their GP which may have affected their mind-set about their work capacity. GPs might not be fully aware of the extent of a patient's sickness absence history as there was no system of documenting self-certification.

It was perceived that the ease of completing a computerised form led to a more detailed, higher quality fit note and facilitated continuity of care between GPs. Templates could potentially be useful in prompting the GP to complete each section however in some cases, certain sections were missing. Some GPs appeared to be creating their own templates, others continued to complete the paper copy and were seemingly unaware of an electronic version or whether they could print off a copy for the patient: 
No - it's not on my template - I've missed that little bit off in my template. So maybe if I were to change my template, it would prompt me to do it more often. (GP_3)

Computerised versions were not available to all GPs. Some were issuing paper fit notes then entering the details onto a template within the computerised medical record. However, completion and accuracy was not necessarily guaranteed:

The problem is you do it by hand and you forget to record it. That happens all the time. $\left(G P_{-} 10\right)$

\section{Completing the fit note fields}

GPs varied in the amount of detail they provided on the patient's condition. Some gave very little, thinking that the less they said the fewer implications it might have, both for the patient and themselves:

My principal is as little as possible. The more you offer, the more it can get the patient into deep water and me into deep water because you end up having to justify these things. (GP_3)

For others it might depend on how they felt 'that day', and who would read the fit note, as to how much detail they would include. Some considered that employers would not understand or might misinterpret medical information. Others recognised that the employer might benefit from more detail, and recognised the need to avoiding medical 'jargon'.

Patients might challenge what was entered, for example if they felt that they needed further justification for sick leave. Some GPs acceded to the patient's wishes, in order to not only maintain a relationship with that patient, but due to fear of the consequences. GPs might be 
deliberately vague about the condition if they felt that more detail might impact on relationships at the workplace, if patients did not want their employers to know about their health condition, or were unsure who might have access to the information. For example the following comment was made regarding a patient with obsessive-compulsive disorder:

She gets very worried about what - if she does take any time off sick, what's put in there - but that's partly related to when she rings in for her own time off before she needs a sick note that they have to leave it on an answer machine which is in an office, which other people can hear. (GP_6)

GPs recognised that their own beliefs and attitudes about disclosure could influence how they completed this section of the fit note. They also admitted issuing fit notes for non-medical reasons such as bereavement, but were uncertain whether this was appropriate.

GPs frequently used the term 'fit note' to refer to 'may be fit' notes, and the term 'sick note' to refer to 'not fit' notes. Some were unclear what to do now thatas there iswas no longer a 'fit for work' note. Others were unsure as to whether the fit note could be used as a 'not fit' and 'maybe fit' note at the same time. In their view a 'may be fit' note might not be appropriate at the time of the consultation, but might be in the near future ${ }_{2}$ so combining both options was seen as a sensible use of the note.

The choices of modifications were generally seen as adequate, although some GPs were reluctant to recommend amended duties as they felt they did not know enough about what these might entail and that 'workplace adaptations' required more specialist knowledge. There was uncertainty about the meaning of the options and the opportunities they offered: 
Sometimes I have trouble distinguishing between them, so "work adaptations", that's easy isn't it? Altered hours - "altered hours and a phased return to work"oh no, altered hours are permanent altered hours isn't it, under duties? Yes, so I suppose that's a bit obvious really isn't it, it's just me being a bit stupid. Yeah, the phased return to work would be a gradual thing - altered hours would be permanent altered hours, permanent amended duties wouldn't it? (GP_10)

Some GPs appreciated the free text comments box to provide more detail, however others hadn't noticed it was there, or thought it unnecessary and too large:

I tend not to use it. I think it's wasted space, because it is quite a big box but it doesn't get used. (GP_5)

Even if this section was perceived as useful, GPs reported that they did not necessarily use it or provide much detail, or realise that it was a requirement to comment on 'may be fit' notes. They were uncertain as to what they were expected to write and varied in their understanding interpretation of the phrase 'functional effects of your condition'. Some were unaware of the wordingphrase. Others did not feel sufficiently confident to comment, feeling that they needed to have an in-depth knowledge of the patient's job.

Functional could be on so many different levels. I think that's a very nebulous term, anyway, and l've actually never put a comment in there because I don't really feel it's my role. (GP_3)

Few GPs used the comment box to provide more information on 'not fit' notes. They thought this might be due to the layout of the note (the comment section is enclosed in the same box as the work modification options) or because they did not feel it to be relevant. Some did consider that 
it might be helpful to the employer to know why the condition was preventing the patient from working.

GPs were uncertain whether employers took much notice of recommendations made on the fit note. Many thought that employers wanted very little information other than to confirm the legitimacy of their employee's absence, and when the employee would be returning to work or to 'cover' themselves if the employee wanted to return to work.

Some GPs thought that the reassessment section was frequently missed because of the fit note design, and suggested improvements such as a tick box or a default question. Others had not noticed this section at all. However, several did not complete it because they didn't think it necessary:

I find this unhelpful, this section here "I will or will not need to assess the patient" I have always found that quite irrelevant, really to be honest.... They just go back automatically, that is why I always find that a bit of useless bit really to be honest. (GP_9)

Some thought that completion could lead to unnecessary appointments, and deliberately left it to the patient to decide. Some-Others had not realised that patients could return to work before the expiry date without being re-assessed, or referred to 'open' and 'closed' certificates, a feature of the previous 'sick note'.

The majority of GPs felt confident in completing the dates section, however others were less sosure, in particular aboutexactly which date the absence started and the return to work date: 
You know what? I think I have a mental blockage on , so 'From' and 'To', I'd sometimes I get - I'm not a hundred percent clear on the return dates. Whether that would that be their last date of sickness - or is that their first date that they're fit to go back to work? (GP_11)

\section{Changing GP behaviour in fit note completion}

Some GPs reported that reflecting on their fit notes in the study had changed their understanding and completion of fit notes. In hindsight they had observed that the content was inaccurate, unclear or not sufficiently detailed. Some realised that they weren't aware of, or hadn't read, some of the sections properly. Some-Others had started to include more comments for employers, which were more constructive and detailed on the condition and how it affected patients' ability to work:

I am tending to put more comments. I put more information for employers in the comments sections. That's the key question - how the condition actually affects the ability to work. So that was quite difficult. That's something that l've changed, obviously.(GP_1)

However this change in practice might not necessarily be sustained, partly because old habits die hard' and also because GPs had no evidence of how effective their fit notes were. They received very little feedback from employers on the usefulness or outcome of their fit notes unless there was a problem. 
Some GPs thought that improving their completion of fit notes was a gradual process. It was still 'early days' and that it would take time, and frequent reminders for GPs to change their habits. It was easy for the GP to avoid the perceived complexities of the 'may be fit' option:

There is a way round this without affecting directly a patient's clinical care. Without getting yourself into trouble. To be frank, you can always put they're not fit for work. (GP_4)

None of the GPs had any occupational health experience or qualification. Few reported having made use of any online resources. Two had attended the National Education Programme in work and health. Their experiences were positive, although it was unclear how much of the programme was directed towards the fit note as these GPs were still uncertain how to complete it. Two GPs had attended a Protected Learning Time event led by one of the Fit for Work Pilot Services which were perceived as useful, but insufficient.

Some thought that fit note training was important, others not. Many considered it unlikely that they would access training that involved their own time and money, or simply weren't interested:

It's not the sort of thing I would go on. I've got a million and one other things I'd prefer to learn, spend an afternoon learning than that, I'm afraid. Sorry. (GP_7)

One of the GPs who had attended the RCGP training valued the opportunity to discuss practice with other stakeholders, or other GPs, which rarely happened:

If you don't know what the people on the other side of the wall are doing, then you can't address the issues perhaps, or you know, you may be sending messages that they don't understand or aren't helpful...often as an experienced GP, some of the 
1

2

3

4

5

6

7

8

9

10 best learning episodes are when you sit round with other GPS and discuss how you do it. So many things in general practice, you're in your room on your own.(GP_6) or had not reviewed it since the fit note was introduced. Some questioned the need for guidance:

No, I wasn't aware of it. Do we need guidance? (GP_5)

However, others felt that standards and guidelines could support their consultations and lead to greater consistency in patient management:

some GPs just issue that (not fit note) because they felt under threat but if there are guidelines and standards you can give that to the patient, "This is not me, this is the guidelines. This is the set of standards that stop me." (GP_2)

\section{Discussion}

\section{Summary}

This study sought to examine GP completion of fit notes through the analysis of three associated data sets. The findings have identified a number of reasons why fit note completion is not meeting expectations.

\section{Lack of motivation to change}

Our findings suggest that GPs would prefer not to be completing fit notes. Many feel unskilled in this area, andthey do not consider it to be their role, a priority, or necessarily interesting. They also feel they do not have sufficient time in the consultation. They doubt whether what they write 
is useful and do not receive any feedback about their performance, either from employers or from their colleagues. These findings are supported by other studies. For example, studies by Wainwright et $\mathrm{al}^{12}$ and Fylan et $\mathrm{al}^{13}$ found that GPs are reluctant to risk jeopardising their relationship with their patient, and that the lack of feedback as to the usefulness of the fit note resulted in a 'consequence vacuum' ${ }^{13}$ Lack of continuity of care and adequate consultation time have been identified by patients as of key importance in the sickness certification consultation in a study by O'Brien et al. ${ }^{14}$ Hussey et a ${ }^{15}$ have also argued the need for policymakers to address the conflicting demands of other stakeholders experienced by GPs in this area. In practice it makes no difference to the GP how well they complete fit notes. There are no obvious incentives or sanctions to change their methods and approaches, and as Welsh et al found, ${ }^{164}$ GPs report that it is difficult to change embedded practice. Previous research has been equivocal about the role of other healthcare professions in issuing sickness certificates ${ }^{175-}$ ${ }^{197}$ and the effectiveness of a recently introduced Allied Health Professions (AHP) Advisory Fitness for Work Report ${ }^{2018}$ has yet to be evaluated. A national government-funded 'Fit for Work' service is currently being introduced in the UK. ${ }^{21}$ As well as offering free health and work advice through a website and telephone line to all stakeholders, it will also offer referral to a free occupational health assessment for employees who have reached, or whose GP expects them to reach, four weeks of sickness absence. If a 'Return to Work Plan' is issued by the service, this can be used in place of the fit note. The findings of this study would seem to lend support to the role of the Fit for Work service, however it is too early to judge the impact it may have on fit note completion. There is a risk that GPs may be less inclined to consider the 'may be fit' option in the knowledge that they can refer the patient to this service after four weeks of issuing 'not fit' notes. 


\section{Lack of knowledge and awareness}

Our findings demonstrate that GPs have not necessarily paid close attention to the changed format of the fit note. Some were unaware that certain sections existed, perhaps due to the design or format of the note. Others were deliberately choosing not to complete them. There was still uncertainty about the lack of a 'fit to work' option and completion of the date fields. GPs were unclear as to how much detail they should include, and of particular concern - whether modifications were temporary or permanent. It is of note that GPs are less likely to recommend | 'altered hours', whereas employers consider these easier to apply. ${ }^{8,22+8}$ GPs are not clear what the phrase 'functional effect of your condition' refers to, despite this being of key interest to employers. ${ }^{230}$ Other studies have reported on the problems experienced by GPs in communicating about patients' function on sickness certificates. ${ }^{24}, 2525$ The study by Fylan et al ${ }^{13}$ also reported on GPs uncertainty in completing the advice fields on the fit note, and 'section blindness'. Despite some sections not being completed in our study, most participants reported that they were completing the notes satisfactorily. This reflects the results of a Swedish survey of physicians ${ }^{263}$ where, despite evidence demonstrating the poor quality of sickness certification, few reported that they needed more skills in completion.

In this study there was also uncertainty about, and lack of standardisation, of computergenerated fit notes. These have the potential to facilitate the compulsory completion of fields as suggested by Skaner et al, ${ }^{274}$ and of ensuring an accurate record of the fit note is held by the GP, even though it may not guarantee better quality. ${ }^{285}$ Non-standardisation of computergenerated fit notes and apparent lack of comprehensive roll-out of the eMed should be urgently addressed. 


\section{Lack of education and training}

In this study none of the GPs had received training specific to fit note completion, nor were they using the interactive too ${ }^{296}$ or on-line fit note guidance provided by the DWP. ${ }^{3027}$ A minority had attended educational sessions related to work and health, but the fit note was not covered in depth. When the fit note was introduced, the government supported the development of a | National Education Programme in work and health ${ }^{3128}$ to be made available to all GPs. ${ }^{3229}$ Although well-received ${ }^{28}$ uptake was reportedly limited ${ }^{8}$ and no objective evaluation has been published. Our findings support those of Welsh et $\mathrm{al}^{1 \underline{64}}$ and Cohen et $\mathrm{al}^{3{ }^{30}}$ that fit notes are perceived to be a low priority by many GPs, and suggest that only those with a particular interest are likely to attend training of their own volition. Previous studies of GPs who have chosen to undertake further training in occupational health have indicated its potential benefit in the completion of sickness certificates. ${ }^{34}$ Although our findings indicate that reflecting on one's own fit notes might encourage GPs to change their completion habits, these might not be sustained. Audit and service evaluations are indicated, and mandatory training considered, with a particular focus on fit note completion. A proposed trial of an education programme for Dutch GPs in this field looks promising ${ }^{35+}$ although it is not clear if the effect of training on the completion of sickness certificates will be measured.

\section{Limitations and strengths}

The main limitation of this study was the small sample of GPs, however the completion of the fit notes in this sample is reflective of other research ${ }^{6,7}$ and the study is strengthened by the use of different data collection methods. Not all GPs submitted the ten fit notes required. We were also unable to achieve the intended sample of 'may be fit' notes despite extending the data collection period, but this low proportion is reflective of the national picture. ${ }^{7}$ 
1

2

3

4

5

6

7

8

9

10

11

12

13

14

15

16

17

18

19

20

21

22

23

24

25

26

27

28

29

30

31

32

33

34

35

36

37

38

39

40

41

42

43

44

45

46

47

48

49

50

51

52

53

54

55

56

57

58

59

60

\section{Conclusions}

Weaknesses in the design and format of the fit note, and the availability of the electronic version, need to be addressed in order to facilitate completion. Consideration of GPs' education and training requirements in fit note completion is urgently required. However as many GPs would prefer not to be completing fit notes, this role should be reviewed.

\section{Conflict of interest statement}

There are no conflicts of interest.

\section{Ethics committee statement}

Ethical approval was obtained from the East Midlands (Northampton) National Research Ethics Committee on $30^{\text {th }}$ May 2013 Reference: $13 / E M / 0186$.

\section{References}

1. Letrilliart $L$ and Barrau $A$. Difficulties with the sickness certification process in general practice and possible solutions: A systematic review. European Journal of General Practice, 2012; 18: 219-228.

2. Waddell G and Burton K. Is work good for your health and well-being? London: TSO, 2006. 
3. Black $\mathrm{C}$ and Frost D. Health at work: an independent review of sickness absence. London: TSO, 2011.

4. Health, Work and Well-being Directorate. Reforming the Medical Statement: Government response to the consultation on draft regulations. The Social Security [Medical Evidence] and the Statutory Sick Pay [Medical Evidence] [Amendment] Regulations. London: Department for Work and Pensions (DWP), 2010. http://webarchive.nationalarchives.gov.uk/20100528142817/http://dwp.gov.uk/docs/refor m-med-stat-govt-response-29jan10.pdf

5. Department for Work and Pensions. Electronic fit note (eMed) - Fact Sheet for GPs. London: DWP, 2013.

http://www.gpcwm.org.uk/wp-content/uploads/2011/05/Fit-Notes-Electronic-Fit-Note-

\section{Fact-Sheet-for-GPs-June-2013.pdf}

6. Coole C, Watson PJ, Thomson L et al. How do GPs complete fit note comments? Occup Med 2013; 65: 575-578.

7. Shiels C, Hillage J, Pollard E et al. An evaluation of the Statement of Fitness for Work (fit note): quantitative survey of fit notes. DWP Research Report 841, 2013.

8. Engineering Employers Federation/Jelf. Sickness Absence and Rehabilitation Survey 2014. http://www.eef.org.uk/NR/rdonlyres/DF6C0296-374E-4863-80D57C0C2682561D/23985/SicknessAbsence.pdf

9. Coole C, Drummond A, Watson PJ et al. Getting the Best from the Fit Note: Investigating the Use of the Statement of Fitness for Work. Institution of Occupational Safety and Health in press

10. Cavanah S. Content analysis: concepts, methods and applications. Nurse Researcher 1997; 4(3): 5-16. 
11. Braun V and Clarke V. Using thematic analysis in psychology. Qualitative Research in Psychology 2006; 3: 77-101.

12. Wainwright $E$, Wainwright $D$, Keogh $E$ et al. Fit for purpose? Using the fit note with patients with chronic pain: a qualitative study. Brit J Gen Pract, 2011; 61: 729-730.

13. Fylan B, Fylan F and Caveney L. An evaluation of the Statement of Fitness for Work: qualitative research with General Practitioners. Research Report No 780. London: Department for Work and Pensions (DWP), 2011.

14. O'Brien K, Cadbury N, Rollnick S, Wood F. Sickness certification in the general practice consultation: the patients' perspective, a qualitative study. Family Practice, 2008; 25(1): 20-26.

13:15. Hussey S, Hoddinott P, Wilson P, Dowell J, Barbour R. Sickness certification system in the United Kingdom: qualitative study of views of general practitioners in Scotland. BMJ, 2004; 328(7431):88.

74.16. Welsh VK, Mallen CD, Wynne-Jones G et al. Exploration of GPs' views and use of the fit note: a qualitative study in primary care. Brit J Gen Pract May 2012 e363-369. 15.17. Niven K. The Potential for Certification for Incapacity for Work by Non-medical Healthcare Professionals. DWP Research Report 225. Leeds: Corporate Document Services, 2005.

16:18. Wynne-Jones G, Mallen CD, Main CJ et al. What do GPs feel about sickness certification? A systematic search and narrative review. Scan J Prim Health Care 2010; 67-75.

17.19. Welsh VK, Sanders T, Richardson JC et al. Extending the authority for sickness certification beyond the medical profession: the importance of 'boundary work' $B M C$ Family Practice 2014, 15:100. 
20. The Allied Health Professions (AHP) Advisory Fitness for Work Report.

http://webarchive.nationalarchives.gov.uk/20130402150350/http://www.ahp.dh.gov.uk/2 $\underline{013 / 03 / 20 / f i t n e s s-f o r-w o r k / ~}$

18.21. Department for Work and Pensions Fit for Work Guidance https://www.gov.uk/government/collections/fit-for-work-quidance

19.22. Lalani M, Meadows P, Metcalf H et al. Evaluation of the Statement of Fitness

for Work: qualitative research with employers and employees. DWP Research Report 797, 2012.

20.23. Kotze E. Employers' views on the fit note. Occup Med 2014: 64: 577-579.

21-24. Krohne K and Brage S. How GPs in Norway conceptualise functional ability. $\mathrm{Br}$ J Gen Pract 2008; 58(557): 835-6.

22.25. Nilsing E, Soderberg E and Oberg B. Sickness certificates in Sweden: did the new guidelines improve their quality? BMC Public Health 2012; 12: 907.

23.26. Lofgren A, Hagberg J and Alexanderson K. What physicians want to learn about sickness certification: analyses of questionnaire data from 4019 physicians. BMC Public Health 2010, 10. 61.

24.27. Skaner Y, Attelov B, Buckland LG, et al. Quality of sickness certification in primary healthcare: a retrospective database study. 2013 BMC Family Practice 14:48.

25.28. Shiels C, Gabbay M and Hillage J. Factors associated with prevalence and types of 'may be fit' advice on fit notes. Brit J Gen Pract March 2014 e137-143.

26.29. Healthy Working UK - Learning Resource. www.healthyworkinguk.co.uk Accessed $8^{\text {th }}$ January 2015.

27.30. Department for Work and Pensions. Getting the most out of the fit note: guidance for GPs. London: TSO, 2014. 
https://www.gov.uk/government/uploads/system/uploads/attachment data/file/349909/fit note-gps-guidance-jan-14.pdf Accessed November 2014

28.31. Cohen D, Khan S, Allen J et al. Shifting attitudes: the National Education

Programme for work and health. Occup Med 2012; 62: 371-374.

29.32. Her Majesty's Government. Improving health and work: changing lives. The government's response to Dame Carol Black's review of the health of Britain's workingage population. London: TSO, 2008.

33. Cohen DA, Aylward M, Rollnick S. Inside the fitness for work consultation: a qualitative study. Occup Med 2009; 59: 347-352.

\subsection{Money A, Hussey L, Thorley K, Turner S, Agius R. Work-related sickness} absence negotiations: GPs' qualitative perspectives. Br J Gen Pract, 2010; 60: 721-728. 31.35. De Kock KA, Steenbeck R, Buijs PC et al. An education programme to increase general practitioners' awareness of their patients' employment: design of a cluster randomised controlled trial. BMC Family Practice 2014, 15:28. 
Table 1. Descriptive statistics for the fit notes received from all GPs

\begin{tabular}{|c|c|c|c|}
\hline Fit notes & & $\mathbf{N}$ & $\%$ \\
\hline \multirow[t]{4}{*}{ Number in sample $(n=94)$ : } & Not fit & 62 & 66.0 \\
\hline & May be fit & 25 & 26.6 \\
\hline & Neither option selected/blank & 6 & 6.4 \\
\hline & Both options selected & 1 & 1.1 \\
\hline \multirow{4}{*}{$\begin{array}{l}\text { Number of fit notes with a single } \\
\text { modification }(n=16) \text { : }\end{array}$} & Amended Duties & 8 & 50 \\
\hline & Phased return & 5 & 31 \\
\hline & Altered Hours & 2 & 8 \\
\hline & Workplace Adaptations & 1 & 0.1 \\
\hline $\begin{array}{l}\text { Number of fit notes with more than one } \\
\text { modification }(n=9) \text { : }\end{array}$ & $\begin{array}{l}\text { Any combination of the above } \\
\text { four modifications }\end{array}$ & 9 & 36 \\
\hline \multirow{4}{*}{$\begin{array}{l}\text { Number of fit notes with comments } \\
(n=27) \text { : }\end{array}$} & 'May be fit' notes & 21 & 77.8 \\
\hline & 'Not fit' notes & 4 & 14.8 \\
\hline & Neither option selected/blank & 1 & 3.7 \\
\hline & Both options selected & 1 & 3.7 \\
\hline \multirow{4}{*}{$\begin{array}{l}\text { Completion of the reassessment section } \\
(n=94) \text { : }\end{array}$} & Not completed & 37 & 39.4 \\
\hline & Will not need to assess patient & 27 & 28.7 \\
\hline & Will need to assess patient & 13 & 13.8 \\
\hline & No review section on form & 17 & 18.1 \\
\hline
\end{tabular}


Table 2. Frequency of fit note comment categories with examples of comments per category

\begin{tabular}{|c|c|c|}
\hline Category & $\begin{array}{l}\text { Examples of GP comments (condition as stated on } \\
\text { fit note) }\end{array}$ & $\begin{array}{l}\text { Number } \\
\text { of fit } \\
\text { notes }\end{array}$ \\
\hline $\begin{array}{l}\text { Work-related } \\
\text { advice/recommendation/instruction }\end{array}$ & $\begin{array}{l}\text { 'If this is possible patient benefits from a set regular shift } \\
\text { which starts preferably later during the day, for example } \\
\text { 11am onwards' (depression) }\end{array}$ & 23 \\
\hline Functional effects of a patient's condition & $\begin{array}{l}\text { 'Ongoing stress, needs to focus on one phone line at a } \\
\text { time to build up confidence, also needs to see occ } \\
\text { health' (anxiety and low mood) }\end{array}$ & 11 \\
\hline Additional information on health condition & $\begin{array}{l}\text { 'After elbow surgery has recovered will need to consider } \\
\text { phased return' (elbow surgery, Asperger's) }\end{array}$ & 8 \\
\hline Clinical management/intervention & 'Advised to rest' (bleeding in early pregnancy) & 3 \\
\hline Date for RTW suggested/indicated & $\begin{array}{l}\text { 'Plan rtw 14/11/13 with some working from home' (low } \\
\text { mood) }\end{array}$ & 1 \\
\hline
\end{tabular}


Table 3. Categories identified by analysis of the GP questionnaire comments

\begin{tabular}{|c|c|c|}
\hline Category & Examples & $\begin{array}{l}\text { Number of } \\
\text { comments per } \\
\text { category }\end{array}$ \\
\hline $\begin{array}{l}\text { The GP commented that he/she could have } \\
\text { provided more information }\end{array}$ & $\begin{array}{l}\text { These GPs commented that they could } \\
\text { have provided more information on for } \\
\text { example: the patient's diagnosis (including } \\
\text { lay terminology); prognosis; cause duration } \\
\text { and severity of the condition; treatment, } \\
\text { including duration; advice on modifications; } \\
\text { the functional effects of the condition; the } \\
\text { patient's occupation. }\end{array}$ & 29 \\
\hline $\begin{array}{l}\text { The GP commented that he/she though no } \\
\text { further information was required }\end{array}$ & $\begin{array}{l}\text { These GPs commented that there was no } \\
\text { further information that could have helped } \\
\text { the patient return to work, or was 'not } \\
\text { applicable'. }\end{array}$ & 14 \\
\hline $\begin{array}{l}\text { The GP commented on their reasons for } \\
\text { issuing a 'not fit' note }\end{array}$ & $\begin{array}{l}\text { These GPs commented that this was } \\
\text { because it was a 'first' note; the patient was } \\
\text { 'avoiding' work; the patient was very } \\
\text { anxious; there was family ill-health; the } \\
\text { patient had already self-certified. }\end{array}$ & 12 \\
\hline $\begin{array}{l}\text { The GP was uncertain as to whether he/she } \\
\text { had completed the fit note satisfactorily }\end{array}$ & $\begin{array}{l}\text { These GPs were uncertain as to: what } \\
\text { information could have helped the patient } \\
\text { return to work; how to refer to work-related } \\
\text { stress; whether a 'fit' note was still required; } \\
\text { whether both 'may be fit' and 'not fit' note } \\
\text { options could be used together; judgements } \\
\text { about amended duties. }\end{array}$ & 12 \\
\hline $\begin{array}{l}\text { The GP commented on their role in } \\
\text { completing fit notes }\end{array}$ & $\begin{array}{l}\text { These GPs commented on: the fitness for } \\
\text { work decision not being seen as the GPs' } \\
\text { role; the challenge of long-term/continuation } \\
\text { fit notes; questioning other GPs awareness } \\
\text { of the 'may be fit' option; the use of national } \\
\text { guidance for sickness absence following } \\
\text { surgery to avoid the need for fit notes. }\end{array}$ & 6 \\
\hline $\begin{array}{l}\text { The GP commented on their reasons for not } \\
\text { providing more detail on the fit note }\end{array}$ & $\begin{array}{l}\text { These GPs did not provide more detail on } \\
\text { the fit note because: they were unsure } \\
\text { about time frames; patients not wanting } \\
\text { their employers to know about their } \\
\text { condition; the diagnosis was unclear; detail } \\
\text { wasn't required on a 'not fit' note. }\end{array}$ & 5 \\
\hline $\begin{array}{l}\text { The GP commented that the patient's return } \\
\text { to work outcome following the fit note was not } \\
\text { as anticipated }\end{array}$ & $\begin{array}{l}\text { In two cases the patient had not returned to } \\
\text { work as expected (one was receiving } \\
\text { further 'not fit' notes from other GPs in the } \\
\text { practice); another was a patient with acute } \\
\text { back pain that the GP had thought would be } \\
\text { 'self-limiting' but who remained off sick; one } \\
\text { had returned to work but had not received } \\
\text { the expected support from her employer; } \\
\text { another had returned to work despite the } \\
\text { GPs expectations. }\end{array}$ & 5 \\
\hline
\end{tabular}


Figure 1. GP questionnaire responses regarding completion of 'not fit' notes ( $n=62$ )

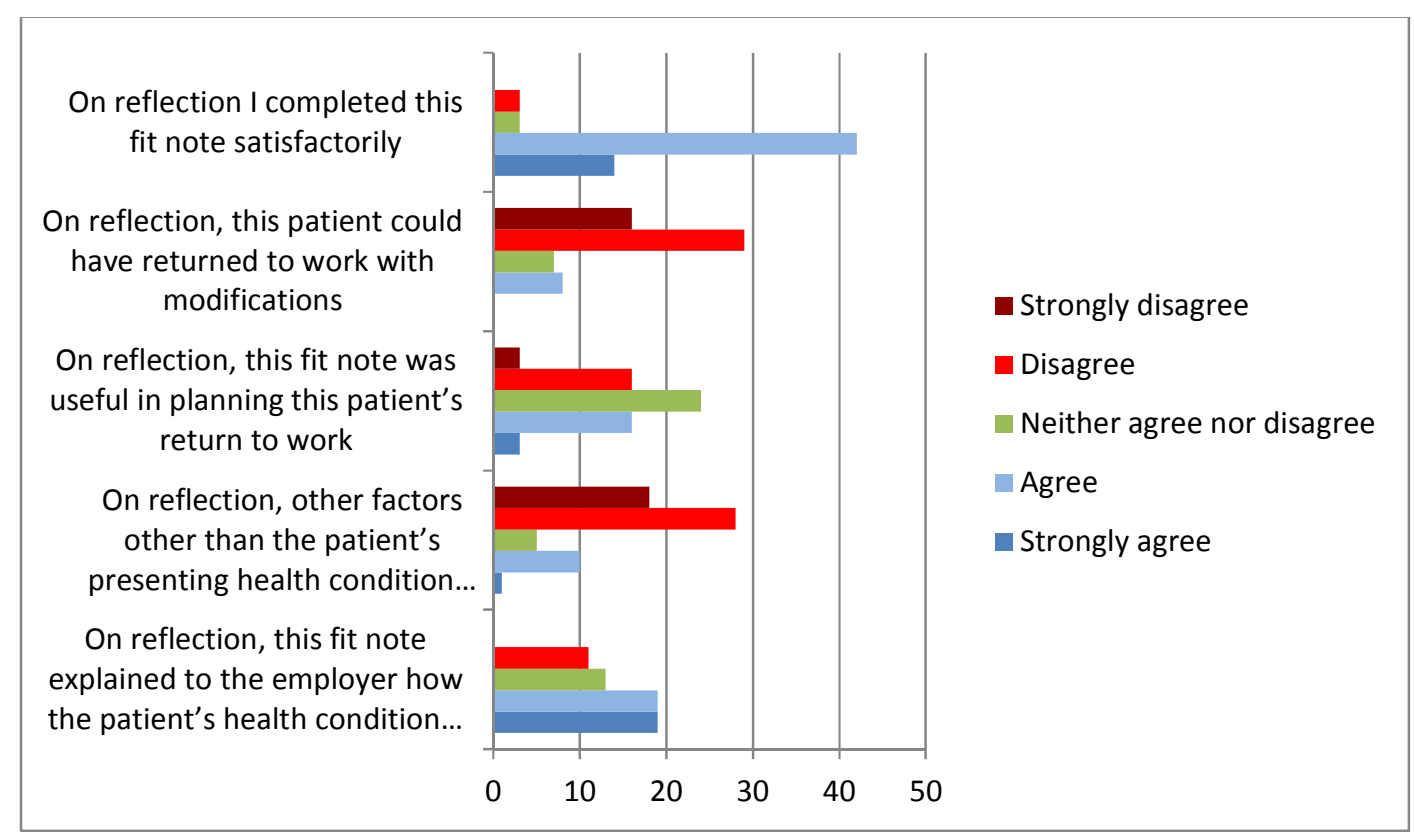


1

2

3

4

5

6

7

8

9

10

11

12

13

14

15

16

17

18

19

20

21

22

23

24

25

26

27

28

29

30

31

32

33

34

35

36

37

38

39

40

41

42

43

44

45

46

47

48

49

50

51

52

53

54

55

56

57

58

59

60

Figure 2. GP questionnaire responses regarding completion of 'may be fit' notes $(n=24)$

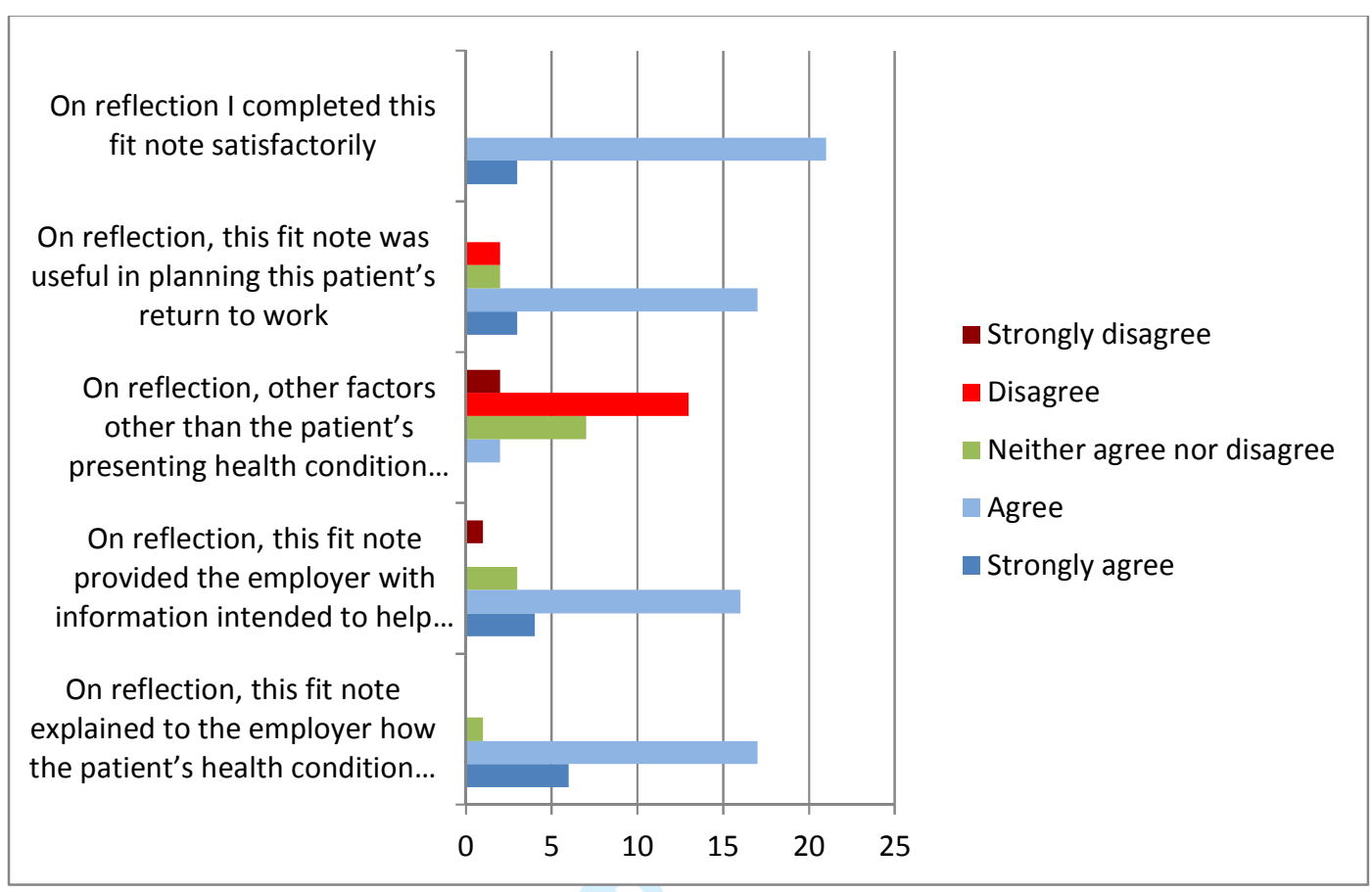

